\title{
Een Brugs Vademecum voor de Rome- en Jeruzalemvaarder samengesteld door Rombout De Doppere 1491
}

Het archief van de Commissie Openbare Onderstand te Brugge bewaart een handschrift dat een merkwaardig document van middeleeuwse vroomheid is. Reeds in 1891 werd een deel van dit handschrift in onze Annales gepubliceerd door Eusèbe Feys, alsdan ondervoorzitter van ons Genootschap. Aan het boek op zijn geheel schonk de uitgever toen niet de aandacht die het verdiende. Met het gevolg dat de eigen aard van dit dietse handschrift al te lang in het duister is gebleven.

De tekstuitgave van het nog onuitgegeven deel van het handschrift is een gelegenheid om de redactie van dit vademecum en de persoon van de redacteur in een nieuw licht te stellen.

\section{Beschrijving van het handschrift.}

Het handschrift is geschreven op papier met een watermerk (Briquet 8087). Het telt 6 katernen van elk 6 bladen; de 36 bladen hebben de afmeting $29 \times 21,8 \mathrm{~cm}$; geplooid in de band geven ze 72 folio's van $21,8 \mathrm{x}$ $14,5 \mathrm{~cm}$. Het slot van elke katern draagt een reclame.

Het geschrift is een vlot cursief, met weinig of geen doorhalingen. De tekst is overvloedig gerubriceerd. Heel het handschrift is van dezelfde hand. Het schutblad draagt alleen vooraan een stempel van de "Hospices Civils" van Brugge.

De perkamenten omslag, waarin de katernen zijn ingenaaid, is gevormd door een ingeplooide akte van 12 maart 1453 (n.s.); zijnde een testament waarin Matthias de Lanc, kapelaan van de St. Donaaskerk, 
genoemd wordt.

Het handschrift is, in al zijn delen, een autograaf van Rombout De Doppere.

\section{De schrijver van het vademecum.}

De persoon van Rombout De Doppere, die tot nu toe in onze biografieën geen plaats heeft gekregen, verdient een ogenblik onze aandacht.

De Doppere was geboren te Brugge, heeft in deze stad geleefd en is er gestorven in 1501. Hij was een geestelijke, priester van het bisdom Doornik. Hij was " in artibus magister", hetgeen wijst op studiejaren doorgebracht waarschijnlijk aan de universiteit te Parijs.

Zijn geboortejaar is niet bekend. Om het benaderend. te bepalen is een getuigenis van hemzelf voorhanden in zijn Brugse Kroniek. Onder het jaar 1491 klaagt hij de hebzuchtige praktijken aan van de kanunniken der St. Donaaskerk; om de waarachtigheid van zijn gezegde te staven voegt hij eraan toe : , sedert meer dan 46 jaar heb ik in de St. Donaaskerk verkeerd..." (1). Zijn betrekking met die kerk gaat dus terug op ca. 1444. Hij is er echter kapelaan noch kanunnik geweest. Zijn eerste betrekking met de kerk in 1444 is mogelijk deze geweest van de jonge choraal, die er koor en kapittelschool heeft bezocht. Dan zou het geboortejaar van de Doppere op ca. 1430 te stellen zijn.

Meyerus, die zelf aan de St. Donaaskerk gehecht was, schrijft ca. 1450 dat De Doppere notaris was en "custos sanctuarii S. Donatiani ".

De opperkoster (maior custos) van St. Donaas was een kapelaan de gremio chori. Deze werd bijgestaan

(1) H. Dussart, Fragments inédits de Romboudt de Doppere, p. II-VI (Brugge 1892; ed. Société d'Emulation). - Als notarıs tekent De Doppere als Rumoldus, soms Romboldus : La Flandre, II, 1868, p. 140. 
door een minor custos of clericus sanctuarii. De functie door Meyerus bedoeld moet deze laatste zijn. De Doppere is immers, zoals gezegd, geen kapelaan van St. Donaas geweest. De koster van de "sanctuarie" was de bewaarder van de kerkschat en de relikwieën.

Hoelang heeft De Doppere dit custosambt waargenomen? Was hij nog custos in 1491, wanneer hij schrijft dat hij 46 jaar in betrekking staat met de St. Donaaskerk?

Het ambt van custos sanctuarii is voor de magister artium, Meester Rombout De Doppere - zoals hij genoemd wordt - maar secundair geweest. Althans vanaf het ogenblik dat hij tabellio d.w.z. apostolisch en keizerlijk notaris geworden is. Het juiste jaar van zijn aanstelling en beëdiging als notaris is eveneens onbekend. Zeker was hij in functie in 1468; in dat jaar schrijft, en tekent hij eigenhandig' het cartularium van de Wateringhe van Moerkerke. Zijn titulatuur is alsdan: "(per me) Romboldum de Doppere, clericum Tornacencis diocesis ac magistrum in artibus, publicum sacra imperiali auctoritate venerabilisque Curie Episcopalis Tornacensis notarium publicum" (2). Het ambt van notaris heeft hij dus gedurende 34 jaar vervuld.

Meyerus heeft in 1540 in zijn latijnse kopie van De Doppere's Vierde Boek de titulatuur van de notaris onvolledig uit het dietse origineel overgenomen: "(finis... IV libri) domini Romboldi Doppere, custos sanctuarii S. Donatiani Brugen et tabellionis, etc." (3). Dit etcetera dekt de hoedanigheid van De Doppere als "secretaris ende scriba" van Gillis de Baerdmakere, de te Brugge residerende suffragaanbisschop van Doornik.

(2) La Flandre, I, 1867, p. 380. - In 1489 tekent De Doppere de notariële akte van translatie der relikwieën in het St.-Janshospitaal te Brugge (Sint-Ursulaschrijn) : zie de tekst bij $\mathbf{J}$. Weale, Hans Memlinc, p. 65-70 (Brugge 1871).

(3) Fragments inédits, p. T4. 
De Baerdmakere, een Brugs minderbroeder, die in de theologie had gedoctoreerd te Parijs, was suffragaan van Doornik met de titel bisschop van Sarepta van 1476 tot aan zijn dood in 1494 (4). Wanneer is De Doppere de secretaris van bisschop De Baerdmakere geworden? Waarschijnlijk is dit in 1482 of 1483 geweest. De Doppere, die de Kroniek van Anthonis De Roovere (Excellente Cronike) in 1482 voortzet, blijkt dit werk te hebben ondernomen met de actieve goedkeuring en medewerking van bisschop Gillis De Baerdmakere. De Doppere zelf getuigt in 1490 op het einde van het Derde Boek van zijn Kroniek : , Twelcke de voornoemde Roelant (lees Rombout) verclaerde het meestendeel van diere ghezien ende ghehoord t'hebben vanden voornoemden meestre Gillis zynen meester zonder eeneghe van partien faveur te draghen..." (5).

Het jaar 1483 is ook het jaar dat de zusters van Emmaüs uit Biervliet het goed ter Stove te Moerkerke aanwerven. Bisschop de Baerdmakere wordt de beschermheer van die zusters, welke zijn bisschopstitel Sarepta in 1486 te Moerkerke zullen overnemen (en later, in de $17 \mathrm{e}$ eeuw, naar Brugge overbrengen). De Doppere was, zoals blijkt uit zijn genoemd Cartularium van de Wateringhe, bekend met Moerkerke. Het is best mogelijk dat De Doppere bij de aankoop van het goed te Moerkerke een rol van makelaar of bemiddelaar heeft gespeeld, terwijl hij reeds als secretaris van de bisschop in dienst was.

\section{De Kroniek van De Doppere.}

Het belangrijkste werk van De Doppere is zijn

(4) Over De Baerdemakere, zie Dom U. Berlière, Les évêques auxiliaires de Cambrai et de Tournai, p. 137-140 (Brugge 1905).

(5) V. Fris, La Cronycke van den lande ende Graefscepe van Vlaenderen de Nicolas Despars, in Bulletin de la Commission Royale d'Histoire, 5e serie, t. XI, 1901, p. 565. F. Vander Haeghen c.s.) Bibliographie d'Antoine de Roovere, p. 29-30 (Gent 1887; overdruk uit Bibliotheca Belgica). 
Kroniek. Een korte behandeling van dit historisch werk zal ook de redactie van zijn Vademecum belichten.

In 1482, bij de dood van Maria van Bourgondië, is De Doppere begonnen met een " bouck" of Kroniek inhoudende de inlantsche ende intestine oorloghen ghesciet int land van Vlaendre tsydert het overlyden van de edele princesse vrauwe Marie...". Gedurende tien jaar, van 1482 tot 1492, heeft De Doppere zijn Brugse Kroniek, in de vorm van een dagboek bijgehouden. De nadruk lag natuurlijk op de militaire gebeurtenissen te Brugge en elders in Vlaanderen, doch tussenin werden ook andere lokale chronicabilia ingelast. De auteur heeft zijn Kroniek ingedeeld in vier boeken : de boeken I en II behandelen de jaren 1482-1487; boek III gaat over 1488-1490, boek IV over 1490-1492.

De vier boeken van de Kroniek waren nog gedurende de 16e en zelfs 17e eeuw te Brugge bekend. Meyerus kon weliswaar ca. 1540 alleen de hand leggen op de boeken III en IV. Doch Despars heeft in de jaren 15601592 de vier boeken gebruikt voor de redactie van zijn Cronycke van Vlaanderen, periode 1482-1492 (6). En nog in 1630 was een handschrift van De Doppere's boek I (en volgende ?) aanwezig in de bibliotheek van de Brugse genealoog Bernard van der Straten (7).

De Doppere heeft zijn Kroniek geschreven in het diets. Het derde boek is in de oorspronkelijke dietse redactie bewaard in het handschrift van de Stadsbibliotheek van Douai en bleef onuitgegeven (8).

(6) Fris, a.w., p. 563.

(7) Kort Verhael van het dierbaer $H$. Bloet... Dit zeldzaam blad, in 1630 opgesteld en gedrukt in 164.1 te Brugge door Nicolas Breyghel noemt, bij een aantekening van 25 oct. 1482 , een „MS. R. De Doppere, ex Bibliotheca D.B. vander Straten". Bernard van der Straten van Brugge, schepen en thesaurier, wapenheraut van de Aartshertogen, had een belangrijke historische en genealogische bibliotheek.

(8) Bibliothèque Municipale de Douai, Ms. 844 van Catalogue Duthilloeul; nieuw nummer 1110. 
Van boek IV heeft Meyerus ca. 1540 currente calamo een soort "copie-résumé" in het latijn gemaakt, met behoud van talrijke typische zinsneden in het diets. Dit compendium van Meyerus, bewaard in de Stadsbibliotheek van St. Omaars, werd in 1892 uitgegeven in de publicatiën in-4 van de Société d'Emulation door P. Henri Dussart. Niet zonder aarzeling meende Dussart dat De Doppere in het latijn geschreven had, hoewel de latijnse tekst van de Fragments duidelijk de stempel draagt van het humanistische latijn van Meyerus.

Het handschrift van boek III van de bibliotheek van Douai was aan Dussart onbekend gebleven (9). Prof. Fris heeft in 1901 dit laatste handschrift, met de oorspronkelijke dietse redactie van De Doppere, bekend gemaakt en de verkeerde voorstelling van Dussart terechtgewezen.

Dit alles wijst op de belangstelling van De Doppere voor geschiedenis in eigen taal. In zijn Vademecum verschijnt hij als de bewerker en vertaler in het diets van een groep teksten in betrekking met de bedevaart naar Rome en Jeruzalem.

\section{Het Vademecum.}

Het handschrift, dat we een "Vademecum voor de Rome- en Jeruzalemvaarder" noemen, is een autograaf van De Doppere en werd geschreven te Brugge. Een kopie van het geheel of van een deel van dit handschrift is, voor zover bekend, in geen openbare bibliotheek voorhanden. In onze literatuur werd het nooit aangehaald. De eerste beschrijving van het handschrift is, zoals gezegd, deze van Feys in 1891.

Langs welke weg en wanneer is de kleine codex in

(9) Hoewel dit handschrift in 1887 door F. Vander Haeghen in de Bibliotheca Belgica (aangehaalde overdruk p. 27-31) beschreven was. 
het bezit van de Brugse Godshuizen (nu Commissie Openbare Onderstand) gekomen ? Dit blijft een open vraag. In de genoemde instelling weet men niets over de herkomst. Blijkbaar is het Vademecum een tijdlang in particulier bezit geweest. De naam "P. Zuerijnc", op de perkamenten omslag aangebracht, wijst misschien in die richting.

Belangrijker is de geschiedenis van de redactie van het handschrift. Heeft De Doppere dit Vademecum bewerkt uit persoonlijke belangstelling voor de bedevaart naar Jeruzalem en naar Rome? Men weet niet dat De Doppere het H. Land zou hebben bezocht. Hij was zestig toen hij het Vademecum samenstelde. Zo hij tevoren naar Jeruzalem was gereisd zou hij, de notaris en memoralist, zeker een eigen dagboek van zijn "voyage" hebben aangelegd. Dat hij de Jeruzalemvaart in zijn laatste levensjaren (na 1493) heeft aangegaan is weinig waarschijnlijk. Anders ligt het met Rome. Het is goed mogelijk dat hij, secretaris van bisschop De Baerdmakere, Rome heeft bezocht. En dat zijn reisdagboek, zoals zijn andere geschriften, verloren is gegaan.

Het Vademecum voor de Jeruzalemvaarder is zeker ontstaan in een milieu waar de belangstelling voor de „Jerusalemsche reyse" zeer levendig was. Verscheidene Brugse tijdgenoten, mensen die De Doppere persoonlijk moet hebben gekend, hadden de reis naar het H. Land ondernomen. Eerst en vooral Anselm Adornes en zijn reisgroep in 1470. Het feit dat De Doppere vóór of in 1491 het latijnse relaas van Adornes' reis in handen heeft gehad, lang genoeg om het in het diets te bewerken, wijst op rechtstreekse of onrechtstreekse betrekkingen met de kring van de Brugse Jeruzalemvaarders (10).

(10) A. Viaene, Vlaamse Jeruzalemvaarders in de Bourgondische eeure, in Biekorf 1964, p. 5-16; met de aanvullingen aldaar p. 119$122 ; 336-338$. 
Tot deze kring behoorden vooral de stadspredikers uit de verschillende mendicantenkloosters. De Doppere heeft zeker omgang gehad met de Carmer Adriaan de Pas, een reisgezel van ridder Jan de Baenst op een tocht die ook de Sinaïberg omvatte. Alsook met de befaamde predikheer en inquisiteur Adriaan de Mil, die in 1486-1487 de H. Plaatsen bezocht. Twee „freremineuren " uit het klooster van bisschop De Baerdmakere, de broeders Antheunis vanden Eechoute en Jaspar Harlais, stadspredikers, voltrokken hun Jeruzalemvaart in 1489 , twee jaar voor de voltooiing van het Vademecum. En wanneer predikheer Jan van der Beke in 1494 met zijn gezellen de pelgrimstaf voor het $\mathrm{H}$. Land opneemt, kan hij de informatie voor de overvaart uit Venetië en voor het bezoek aan de $\mathrm{H}$. Plaatsen gaan overschrijven uit het dietse Vademecum van De Doppere dat een collectieve ervaring van 25 jaar Brugse Jeruzalemvaart praktisch samenvat.

\section{Samenstelling van het Vademecum.}

In zijn handschrift heeft De Doppere de volgende vier stukken samengebracht :

1. de reisbeschrijving van Adornes uit 1470;

2. de informatie voor de Jeruzalemvaarder op de galei van Venetië;

3. de aflaten verbonden aan de $\mathrm{H}$. Plaatsen in Palestina;

4. de aflaten te verdienen te Rome.

Het "Voyage" van Adornes.

De Jeruzalemvaart van ridder Anselm Adornes, ondernomen vanuit Brugge over Genua, Tunis en de Sinaï, duurde meer dan 13 maanden (14 februari 1470 - 4 april 1471). De terugreis liep over Rhodos tot Brindisi per schip; dan over land tot Brugge via Bari, Napels en Rome.

Tot het reisgezelschap behoorde de zoon van ridder Anselm, Jan Adornes, die te Padua studeerde. Door 
Jan Adornes werd een latijns dagboek van de reis opgesteld: Itinerarium in Asiam et Africam. De tekst van dit Itinerarium is bewaard in een handschrift van de Stadsbibliotheek van Rijsel (nr. 187 van de Catalogue Le Glay; nr. 519 volgens de Catalogue des bibliothèques de France). Weled. $B$. van de Walle bezit een kopie van deze tekst. De Bibliothèque Nationale van Parijs was in de vorige eeuw in het bezit van een versie van het Itinerarium die vollediger was dan deze van het Rijselse handschrift. Van dit Parijse handschrift, dat nu verloren is, wordt een gedeeltelijke kopie bewaard op de bibliotheek van de Facultés catholiques te Rijsel (cote 2 M 17) (11).

$\mathrm{Bij}$ de verdietsing van het Itinerarium heeft $\mathrm{De}$ Doppere de personalia betreffende Adornes en zijn reisgezellen bijna geheel weggelaten. Hij behoudt de nauwkeurige beschrijving van de reisroute met al de nuttige inlichtingen voor de reiziger. Uit het latijnse reisverhaal is, onder de hand van De Doppere, een diets reisboek voor de Jeruzalemvaarder ontstaan.

De titel van de bewerking is : "Tvoyage ghedaen te Synay ende te Jherusalem by mer Ancelmus Adournes" (12).

Van dit ingekort reisboek geeft De Doppere, als aanhangsel, nog een samenvatting in een paar bladzijden onder de titel: „Dit es een abriget dats int corte bescreven vander reyse zo hier naer volcht" (13).

De route over Genua, door Adornes gevolgd, was weliswaar niet de meest gebruikelijke, de regelmatige

(11) Over de reis van Adornes publiceerde B. van de Walle een uitstekende studie (Voyages de quelques brugeois en Egypte et en Palestine au XVe et au XVIIe siècle) in Ad Harenas, Gedenkboek van het St.-Lodewijkscollege, p. 260-272 (Brugge 1960) met belangrijke bibliografie. Zie Biekorf, 1964, p. 9-10.

(12) Uitgeven dior E. Feys in Annales de la Société d'Emulation 41, 1891, p. 149-213.

(13) Uitgegeven idem p. 213-217. 
afvaarten van de galei uit Venetië naar Jaffa en de reisvoorwaarden trokken veruit de meeste Vlaamse Jeruzalemvaarders naar de Dogenstad. Voor deze laatste klassieke reisroute bewerkte De Doppere een verdietsing van de: "Informatie" van de Jeruzalemvaarder (14).

\section{Het Regement van de Jeruzalemvaarder.}

De dietse tekst van dit Regement is verwant met gelijktijdige Engelse teksten, nl. de: "Informacon", een versie die dateert uit 1480-1490. Sommige woorden schijnen een Frans voorbeeld te veronderstellen. De redactie van De Doppere is duidelijk Westvlaams en Brugs gekleurd. Van de dietse versie van De Doppere is, voor zover we weten, geen tweede handschriftelijk getuige bewaard.

Was er omstreeks 1500 een gedrukte tekst (in welke taal ?) van de "Informatie" in omloop? Dit is niet onmogelijk. De Brusselse poorter Pieter de Smet gezeid van Steebroeck, die in 1505 over Venetië naar JaffaJeruzalem reisde, heeft blijkbaar een tekst van de Informatie in handen gehad (15). Ook Jean Zuallart uit Ath, leermeester van Filips van Merode, neemt in zijn reisverhaal de inhoud van de Informatie op (16).

De aflaten van Jeruzalem en het $H$. Land.

De tekst van De Doppere bleef tot nu toe onuitgegeven.

De Doppere schijnt een Frans of een Latijns model in handen te hebben gehad. Was de tekst van deze par-

(14) A. Viaene, Informatie voor Jeruzalemvaarders in dietse versie, in Biekorf, 1963, p. 1-8.

(15) J. de Saint-Genois, Les voyageurs belges du XIIIe au XVIe siècle, I, p. 200-201 (Brussel 1846).

(16) Zelfde werk II, p. 39-40. 
doenen , met kruisjes" en Latijnse oratiën reeds ergens in druk verschenen? In handschrift was deze tekst zeker geen zeldzaamheid. In het relaas van zijn reis in 1422 heeft Guillebert de Lanoy een zeer uitvoerig hoofdstuk over deze aflaten opgenomen. De tekst van zijn cataloog begint als volgt: „Cy s'ensieuvent les pardons et indulgences et les pelerinaiges qui sont dedens la cité de Jherusalem ". Daarop volgt een eindeloze lijst van heilige plaatsen heel Palestina door en tot in Syrië (17). De lijst van De Doppere is daartegenover zeer bescheiden.

In de volgende tekstuitgave (Bijlage I) worden de klassieke Latijnse oratiën alleen met de initia en de conclusie opgegeven. E.:

\section{De Aflaten van Rome.}

Heeft De Doppere zijn uitvoerige beschrijving van de Romeinse kerken uit het latijn vertaald naar een gedrukt exemplaar van de Mirabilia Urbis Romae? Een Romeinse druk van deze Mirabilia was in 1489 (en vroeger?) reeds in de handel; deze reisgids voor de Romevaarder beschreef ook de lokale aflaten (18).

Blijkbaar heeft De Doppere de tekst van een dietse versie van de Aflaten van Rome onder ogen gehad. Zijn eigen dietse versie schijnt echter geen (bijgewerkte) kopie te zijn van de Beschrijving van de Romeinse kerken die in 1377 door de Augustijnermonnik Leopold van Wenen was opgesteld (19) en waarvan

(17) C.P. Serrure, Voyages et ambassades de Messire Guillebert de Lannoy 1399-1450, p. 56-64. (Mons 1840; Soc. Bibliophiles de Mons, $\left.\mathrm{n}^{\circ} 10\right)$.

(18) Brunet, Manueel du libraire, Supplément I col. 1034; Il col. 1062 .

(19) N. Paulus, Geschichte des Ablasses bis zur Mitte des 14. Jahrhunderts, II, 301 (Paderborn 1923). 
een dietse overzetting uit 1378 bekend is (20).

De versie van De Doppere biedt in elk geval genoeg afwijkingen van de bekende redacties om hier op haar geheel te mogen gepubliceerd worden. In het vademecum beslaat het stuk over de aflaten van Rome de bladzijden 62-72. De tekst ervan wordt hierna (Bijlage II) helemaal ongewijzigd naar het handschrift afgedrukt, met uitzondering van de verkortingen, die opgelost werden.

A. VIAENE

\section{B I J L A G E I}

\section{De aflaten van Jeruzalem en het $H$. Land.}

Hier naer volghen oratien diemen leist up alle devote plaetsen die staen binder stede van Jherusalem ende daer buuten. Ende daer teeken staet van eenen gheheelen cruce daer es oflaet $\mathbf{A}$ pene ende a culpa. Ende daer maer staet een half cruce daer es oflaet van vij jaren, alst blyct.

In Nazareth Annunciacio

Missus est angelus. Deus qui de beate.

Up den berch Thabor van de transfiguracie

Nemini dixeritis visionem. Deus qui unigenitum.

Int dal van Josaphat daer onse vrauwe begraven was Vox turturis audita. Concede... fragilitati nostre.

Vander plaetse daer onse vrauwe starf + Ave Regina celorum. Veneranda nobis Domine.

(20) De aflaten der zeven kerken van Rome, volgens een nederduitsch Handschrift der XIVe eeure, berustende in de Kon. Boekerij te's Hage. Uitgegeven in Archief voor kerkelijke geschiedenis inzonderheid van Nederland (= Kist en Royaards' Archief, VI, p. 303--318; Leiden 1835). De uitgever stelt (p. 305) het jaar 1374 voor als datum van de redactie. - Een fragment uit deze uitgave (De Sint Jans kerk te Rome) opgenomen in (J. van Vloten) Verzameling van nederlandsche prozastukken van 1229-1476 naar tijdsorde gerangschikt, p. 6688 (Leiden 1851). 


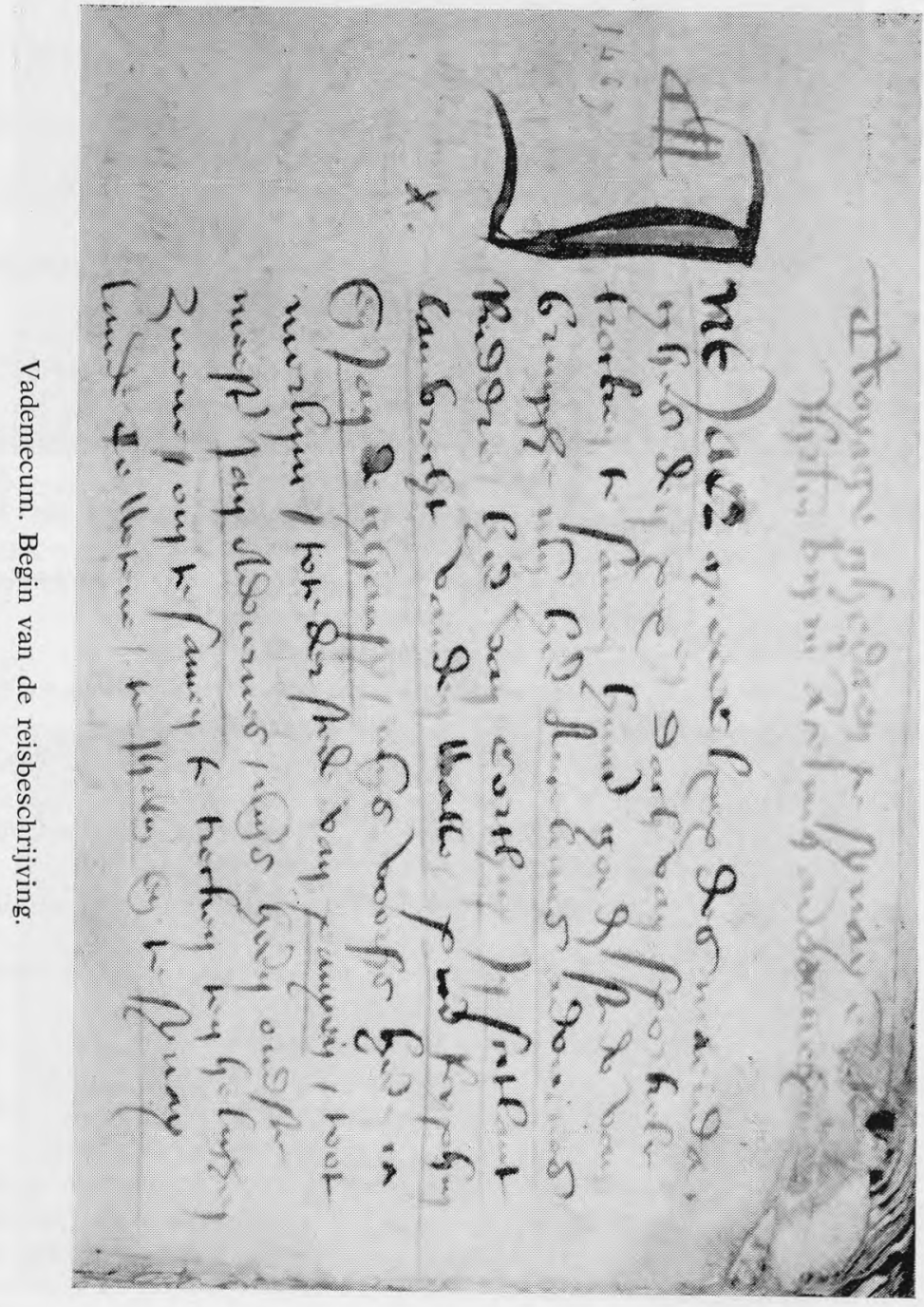




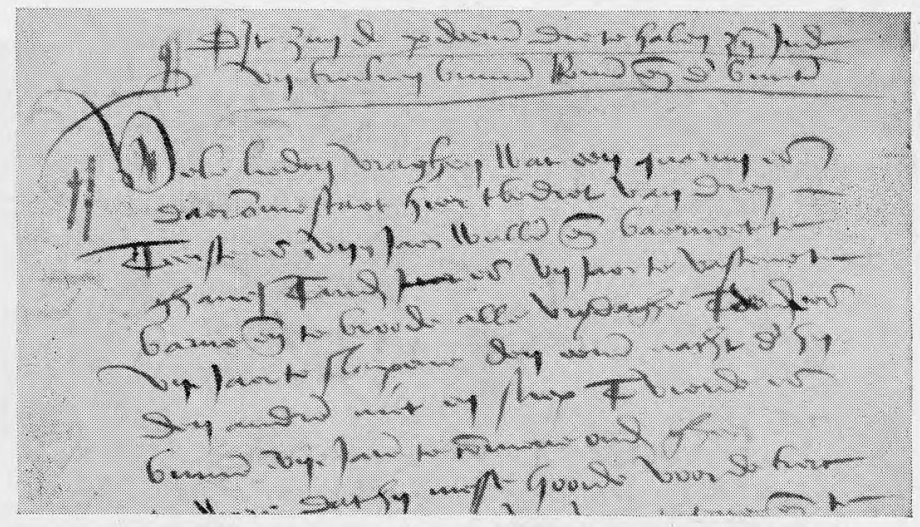

Vademecum fol. 62: Dit zijn de pardoenen (incipit)

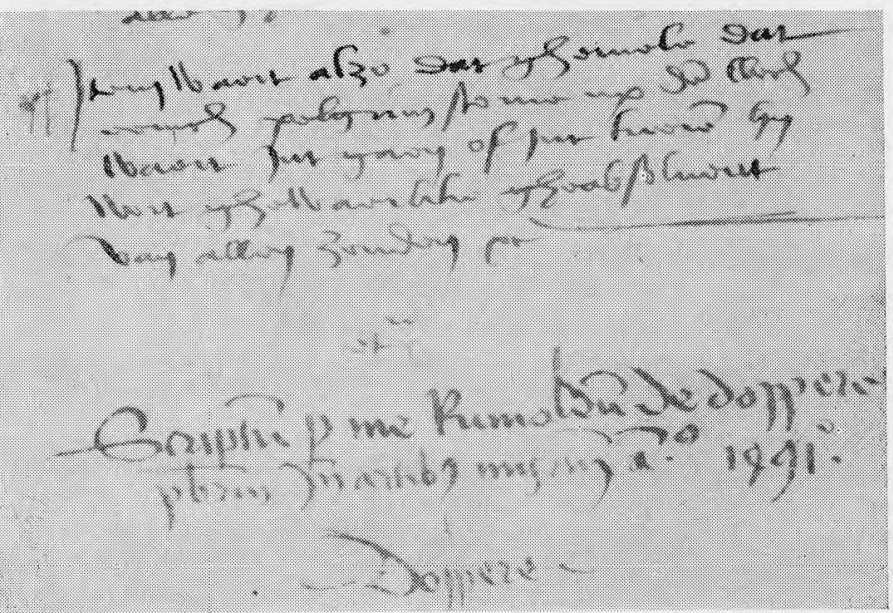

Vademecum fol. 72 : Slot en handtekening van De Doppere. 
Daer ons vrauwe gheboren was +

Nativitas tua. Supplicationem servorum tuorum.

Vanden pardoenen up de plaetse inde kerke

van bethleem daer ons heere gheboren was

Angelus ad pastores. Concede... ut nos unigeniti.

Item ter crebbe

O magnum misterium. Deus qui hanc sacratissimam noctem.

Item ter besnidenesse

Mirabile misterium. Omnipotens... dirige actus.

Up den berch van Calvarien

'Tenebre facte sunt. Domine J. C.... qui hunc sacratissimum locum.

Daer ons heere ghesalft was

eer men begrouf ende int graf leyde

Unguentum effusum nomen tuum. Dulcissime J. C.

Ten grave ons heeren

Quem totus mundus. Domine J. C. qui hora diei.

Daer tcruce christi vonden was

$O$ crux gloriosa. Deus qui in praeclara.

Ten huuse van pilatus

Ingressus pilatus. Respice... super hanc familiam.

Ten berghe van oliveten

daer ons heere ten hemel clam

O rex glorie. Concede... ut qui unigenitum.

Ter gouden poort

Ceperunt omnes turbe. Da... ut qui in tot adversis.

Item

Ductus est Jhesus. Respice... familiam tuam.

Daer lazarus verwect was

Magno salutis gaudio. Adiuva nos Deus salutaris.

Ter fluvio Jordane

Baptizat miles christum. Deus cuius unigenitus.

Vanden sacramente

O sacrum convivium. Deus qui nobis sub sacramento.

Vanden helighen gheeste

Veni sancte spiritus. Assit nobis... virtus spiritus sancti.

Van sinte mathys

Hoc est preceptum meum. Deus qui beatum Mathiam.

Anime omnium fidelium.

A subitanea et improvisa morte... Amen. Etc. 


\section{B I J L A G E II}

\section{De aflaten van de kerken van Rome.}

(f. 62) „Dit ziin de pardoenen die te halen zijn in de .vij. kerken binnen Rome, ende daer buiten.

(Nota over de carena).

Vele lieden vraghen wat een quarijn es daeromme staet hier tbediet van dien.

Teerste es .vij. jaer wullen ende baervoet te ghaene.

Tander es .vij. jaer te vastene te barne ende te broode alle vrijdaghe.

Tderde es .vij. jaer te slapene den eenen nacht daer hij den andren niet en sliep.

Tvierde es binnen .vij. jaren te commene onder gheen dac ten ware dat hij messe hoorde voor de kerc duere.

Tvijfste es .vij. jaer tetene ende te drynckene huut den scuetele daer hij zyn ghevouch in dade.

So wie alle dese pointen vuldoet .vij. jaer hij windt een quariin. Ende dit mach men halen te Rome zonder ghetal.

Zalich zijn zy, die ze halen moghen dese grote gracien.

(De aflaten in de zeven Basilieken).

Ghy moet weten dat binnen Rome zyn iij.c ende lvij kerken daer men alle daghe messe in doet, onder de welke daer zyn .vij. kerken voor alle dandere gheprevilegiert met gracien ende met helicheden ende heeten coninclike kerken zijn zy van paeusen ende van keysers ghesticht.

(De Sint-Pieterskerk).

Onder de welke de eerste es Sinte pieterskerke (f. 62v) dappostele ende es ghestelt ter plaetse daer sinte pieter ghecruust was, ende die heet men locus vacitanus (sic). Ende es ghestelt anden voet vanden berghe zo datmen daer toe clemt met eenen grade xxviij trappen hooghe. Ende alzo dickent alsmen die trappen up clemt ende neder daelt telken heefftmen quite tsevenste deel van ghezetter penitencie vanden paeus alexander.

Als een mensche comt voor de kerke daer de fonteyne staet, so zietmen boven der duere $\mathbf{j}$ belde van onsen heere tusschen zynen roeten staet $\mathbf{j}$ van den penninghen daer god omme vercocht was. Alzo dickent als $\mathrm{j}$ mensche dien penninc anziet zo heift hy xiiij.m. jaer aflaet.

Inde vorseide kerke zyn C. outaren ende tot elken outare zyn xlviij jaren aflaeten ende alzo menich quarijn. Ende vij. outaren zynder die gheprevilegiert zyn met gracien ende met helicheden. 
Deerste outaer daer de veronike up staet heift vijc. jaer aflaets. Ende doutaer van sinte Andries heift $v^{c}$. jaer aflaets. Ende doutaer van onser vrauwe heift $\mathbf{v j}^{\mathrm{c}}$. jaer aflaets. Ende den outaer van sinte leo daer hij ontfync dabsolucie in zyner messe vanden hemele die heift $v j^{c}$ jaer aflaets. Ende doutaer van alle zielen heift $v^{\circ}$. jaer aflaets ende up heleghe daghen (f. 63) een ziele huuten vagheviere. Ende doutaer van sinte Symoen sinte Juden $\mathbf{v j}^{\mathrm{c}}$ jaer oflaets.

Ende inde wederzijde vanden choor deure staen twee crucen. So wie die crucen cust heift xij $^{\circ}$ jaer aflaets.

In onser vrauwen daghe inde vastene so hanctmen daer een cleed boven in den tor dat de moeder gods zelve maecte, ende dat hanct daer tot onser vrauwen daghe half ougst. Alzo menichwaerven als een mensche dat cleedt anziet, zo heift hy xiiije. jaer oflaets ende alle hooghedaghen dobbelerende. Ende alzo dickent als $\mathbf{j}$ mensche gaet metten sacramente, datmen den zieken lieden draecht, zo heift hy $\mathrm{xv}^{\mathrm{c}}$. jaer oflaets.

Item de paeus silvester gaf alle den ghuenen die elcx daechs ten drien kerken commen zoude oedmoedelike quite tderden deel van ghezetter penitencie ende van vergheten zonden. Ende xviije. jaer oflaets ende alzo menich quarijn.

Ende vanden hooghen outare daer tlichame van sinte pieter rust, daer of gaf de paeus gregorius oflaet van allen vergheten zonden zonden ende van allen achterghelaten beloften, handt of voet, an vader of moeder ghedaen, in evelen moede, xxviij jaer (f. 63v) oflaets ende alzo menich quaryn.

Ende van ons heeren upvaert tot onser vrauwen daghe thalf ougste, zo machmen daer halen xiiijc. jaer oflaets ende alzo menich quaryn.

Item in de feesten van sinte pietre heltmen daer iijm. jaren oflaets, inde octave van sinte maertine als de voorseide kerke ghewijet was haeltmen daer vijm jaer oflaets ende alzo menich quarym, ende tderde deel van ghestelder penitencie alle de ghuenen die daer zyn vanden landen.

Ende alle de ghuene die daer commen zyn van anderssyden sbeerchs die zyn ghedobbleert van gracien.

Ende alsmen de veronike toocht zo hebben die van Romen $\mathrm{vm}$. jaere oflaets ende die vanden lande $i x^{m}$. jaer oflaets, ende die van bezyden sberchs xiiijm. jaer oflaets ende alzo menich quaryn ende verlatenesse tderde deel van allen zonden.

An sinte pieters kerke an deen zyde daer licht een kerchof dat men heet gods acker daer in dat men graeft de pelgrims, daer en machmen niement anders in begraven, dat is tlandt (f. 64) 
daer de $\mathrm{xxx}$ penninghen over ghegheven waren.

(Sint-Paulus buiten de muren).

Item in de kerke van sinte pauwels buuten mueren, daer zyn hooft ghevonden was, haeltmen xlviijm jaer oflaets ende alzo menich quaryn.

Inde feeste van sinte pauwels haeltmen daer .M. jaer oflaets, in zyne bekeerynghe .C. jaer oflaets, in alder kinderen daghe $\mathrm{xl}^{\circ}$. jaer oflaets.

Inde octave van sinte maertins als de kerke ghewijt was xiiij $^{c}$. jaer oflaets ende alzo menich quaryn, ende tderdendeel van allen zonden quite.

Ende wie alle zondaghe visenteirt de kerke van sinte pauwels hij heift alzo vele oflaets als of hy ghynghe tsinte Jacops in galissien ende wederquame van daer.

(Sint-Laurentius buiten de muren).

Item inde kerke van sinte lauwereyns buuten den mueren daer rustet lichame van sinte lauwereyns ende van sinte steven. Ten hoogten outare haeltmen $\mathrm{xvm}$ jaer oflaets ende alzo menich quaryn.

De ghuene die visenteirt dandere outaren die inde kerke staen, die heift vije jaer oflaets ende alzo menich quaryn.

Ter kercwiynghe haeltmen daer iiijm jaer oflaets (f. 64v) ende alzo menich quaryn. In haerlieden feeste $\mathrm{c}$ jaer oflaets.

De paeus pelagius gaffert halene ten viere feesten vanden jare vijm jaer oflaets ende alzo menich quaryn.

Ende wie dat daer comt alle woensdaghe midden in de weke verdient te verlossen een ziele huuten vagheviere ende hem quite van allen zonden.

(Sint-Kruis van Jeruzalem).

Item inde kerke van sinte cruus, daer es eene cappelle binnen besloten, daer was ghestelt sinte helenens wieghe skeysers constantyns moedre, de welke cappelle de paeus silvester hiet Jherusalem, daer es den band daer christus mede gheleet was toten cruce, ende twee saphieren, deene vul van christus bloede, ende dandre van onser vrauwe melcke, ende de sponge daer mede dat gheminghel was azyn met galle ende de naghelen daer god mede ghecruust was ant cruce, ende een groot deel vanden bebloeden cleede daer sint jan baptiste up onthooft was, ende twee aermen van sinte pieter ende van sinte pauwels ende daer es thooft vanden paeus amedeus (?) die ghemartelyt was.

Inde cappelle die men heet Jherusalem voor den hooghen outaer daer staet de zetel daer hy in (f. 65) ghemartelyt was by den inghel van hemelryke, by zyns zelfs consente, dat hyt behoude dat hyt verdient hadde jeghen gode onsen heere. Ende daer gaf hy 
hem allen die inden zetel quamen zitten tderdendeel van allen zonden quite. Ende $x v m$ jaer oflaets ende alzo vele quarynen. Ende allen hooghen daghen ghedobbleert.

Ende de paeus stephanus die daer ghedoodt was inde cappelle diemen heet Jherusalem die gaf daer oflaet van allen zonden ende quite van allen penitencien.

(S. Maria de Meerdere).

In onse vrauwe kerke te maior dats inden hooghen outaer daer es tlichame van sinte mattheeus, daer haeltmen xiiijm jaer oflaets ende alzo menich quariin. Ende inde andre outaren es tlichame van sinte Jeronimus ende daer es van christus wieghe daer hy in lach, ende van sinte thomaes aerme ende van onser vrauwen melcke, ende een groot deel vanden houte des crucen ende van menighen helighen lichame, daer haeltmen xlviijm jaer oflaets ende alzo veel quarynen.

Ende de iijde paeus Nicholaus ende de viijste paeus gregorius die gaven daer $\mathrm{x}^{\mathrm{m}}$ jaer oflaets ende alzo vele quarynen die de voorseide kerke visenteirden.

(f. 65v) Hem van ons heeren upvaert tot anden wintere zo haeltmen daer xiiijm jaer oflaets ende alzo veel quarynen. Ende alle helighe daghen ghedobbeleert, ende verlatenesse tderdendeel van allen zonden.

(Sint-Sebastiaan).

Item in sinte sebastiaens kerke buten mueren int kerckhof des paeus calixtus ter stede diemen heet cakabundas daer dinghel ons heeren hem openbaerde ende sprac te den paeus sinte gregorius, in deze stede es waerachtig oflaet van allen zonden ende van allen penitencien, eeuwelic blivende ende blyscap zonder hende.

Ten hooghen outaere vander kerke daer haeltmen xxviijm jaer aflaets ende al zo veel quarynen ende tderdendeel van allen zonden quite. Ende die dandere outaren visenteirt die heift vij ${ }^{c}$ jaer oflaets. Ende inden achtersten outaer vander kerke daer es xiiij jaer oflaets daer leicht $\mathbf{j}$ helich paeus begraven ende heift een ijzeren traelge over hem, die dien visenteert met een Ave maria heift $x^{\mathrm{c}}{ }^{\mathrm{c}}$ jaer oflaets.

In deze kerke staet een duwiere onder deerde (f. 66) daer de xij apostelen ghevloon waren ende alle gods vrienden deur de vreese vanden dood, daer staen .ij. outaren, alzo dickent als $\mathbf{j}$ mensche daer duer gaet hy heift xiiij ${ }^{\circ}$ jaer oflaets ende alzo menich quaryn. Ende alle hooghe daghen dobbelerende. De paeus pelagius gaf daer toe xlviij jaer oflaets ende alzo menich quaryn.

Ende achter de kerke staet een kelder daer in dat ligghen xlviij paeusen die alle martelaeren storven om gods wille, wie dat daer 
eerst waert in comt die haelt .vij. zielen huuten vagheviere ende alzo vele oflaets dat alle de werelt niet en zoude connen ghesommeren dan god alleene.

Upden iiijen zondach in majo zo haeltmen daer eene ziele huuten vagheviere. Ende inden kelder staet een pit, daer sinte pieter ende sinte pauwels in laghen bedect $\mathrm{ij}^{\mathrm{e}}$ ende 1 . jaeren dat noyt man en wiste dat zy ghevloon waeren. So wie zyn hooft indien pit steict ende weder huut trect hy es reyne van allen zonden.

Van ascencioens daghe tot ingaende ougst zo haeltmen daer

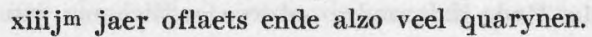

(f. 66v) De paeus gregorius, de paeus Silvester, de paeus Alexander, de paeus ........(?), de paeus pelagius ende de paeus honorius die gave ele van hemlieden $\mathrm{x}^{\mathrm{m}}$ jaer oflaets ende zo menich quaryn.

Ende ligghen vele helighe lichamen van anderen helighen apostelen maertelaren ende confessoren ende maechden daer te lanc of te scrivene ware, daer omme zijn de graven daer zo groot dat zy niet te gronderen noch te vertellen en waren.

(Sint-Jan in Lateranen)

Item in sinte Jans kerke te lateranen, daer gaven die paeuzen gregorius ende silvester doemen de kerke wyen zoude, zo en zacht noyt man zo zeere reynen alst dede up dien dach, de paeus silvester gaf alzo menich jaer oflaets alst up dien dach menich drepel waters reynde. Ende alse hyt ghegheven hadde, doe bepeinsde hy hem of hys machtich ware dat oflaet te ghevene, doe quam een stemme vanden hemele ende zeide, paeus silvester du beste wel machtich dat oflaet te ghevene ende de pardoenen die du ghegheven hebs (f. 67) ende god die gheifter alzo vele daer toe.

Ende alle de ghuene die sint jans kerke visenteren dat orcond de paeus bonifacius ende seicht : So wat menschen die sint jans kerke visenteren, wat zoude hij zoucken ten helighen grave want hij en heift gheen nood te ghane, ware eenich mensche die trecken zoude ten helighen grave, ende tgoed niet en hadde, ghynghe hy van sinte pieters tot sinte jans te laterane, hy ware gheabsolveirt, mi en rouct wane hy comt, of te welke tijt dat hy comt, te sinte jans te laterane es hy quyte ende vry van allen zonden indien dat hy berau heift.

Salich es de moeder die tkint drouch dat zaterdaechs tsinte jans te laterane messe hoort, hy verledicht alle de ghone die hem bestaen tote lxxvijten lede uuten vagheviere, Noch haelt hy alzo veel oflaets dat alle de weerelt niet en zoude connen ghesommeren dan god alleene. 
(f. 67v) Upten tor vander voorseider kerke daer staet een dobbel cruce, dat was ghemaect vanden zweerde daer sint jan baptiste mede onthooft was. Alzo dickent als $\mathrm{j}$ mensche dat an ziet zo heift hy xiiij jaer oflaets.

Ten hoghen outare haeltmen quite van allen zonden.

Onder der crocht daer staet onder tgraf daer sinte jan ewangeliste in ghync ligghen als hy messe ghehaen hadde, daer comt alle goede vridaghe tsnachts van gods weghe olye ende crisme die die van Rome oorboren. So wie zyn hooft daer in steict hy heift xiiij ${ }^{c}$ jaer oflaets ende alzo vele quarynen.

Ende achter den hoghen outaer daer staet een zetel daer god zelve in zat ende sint jan. So wie daer in zit hy heift tderdendeel quyte van allen zonden.

Die doutaren vander kerke visenteirt die in die kerke staen die heift xlviij jaer oflaets ende alzo menich quaryn.

(f. 68) Inde sacristie daer staet sint jans outaer ende de tafle daer ons heere up hat in witte donderdaghe, ende de steenen tafle die ons heere moysesse gaf ende vele andre reliquien ende helichdommen.

Ende daer zyn twee zilveren ampullen daer es in vanden bloede ende vanden watre dat liep huut christus zyde als hy hyne an thout des crucen.

Ende daer es een cruce dat quam van over zee in een steenen scip alleene te Romewaert daer es in $\mathbf{j}$ helich reliquie dat onsen heere toebehoorde, es huuten tempel ons heeren, zijn .iiij. coperen calommen die staen in wederzyde vanden hooghen outare, daer es in vanden .v. gheerstenen brooden ende ij. visschen daer mede dat ghevoet waren $\mathrm{vm}$ volex. Ende daer es in vander besnidenesse ons heeren in onser vrauwen hooftcleedt. Daer es in dat hemelsche broodt dat ghevonden was binnen sint jans grave (f. 68v). Ende vele andre reliquien die daer in vele ziin zonder ghetal.

In die sacristie haeltmen tderdendeel quyte van allen zonden.

Item in de zelve kerke staet $\mathbf{j}$ cappelle ende heet sancta sanctorum, daer in zietmen ons heeren openbaringhe in sinte luucx tijdt.

Ende boven den hooghen outaer zijn de hoofden van sinte pieter ende sinte pauwels. Ende daer zyn de lichamen van vele andre zanten, daer haeltmen $\mathrm{xvij}^{c}$ jaer oflaets ende alzo vele quarynen.

In dien tyden als de keyser constantyn ghedoopt was zeide hy tote den paeus silvester : in dien dat ic myn huus ghgheven hebbe gode teeren, ende gheift mildelic uwe gracien hem allen die hier commen toot deser stede, daer andwoorde de paeus silvester : ons heere ihesus christus by zynre grote ontfaermicheyt heift hu ghezuvert van alder lazerie, hy moetse alle zuveren van zonden 
de ghone die commen verzoucken dese stede. Diet niet en wille gheloven die ga tot sint jans in de kerke hy zult daer (f. 69) vynden ghehauwen in eenen zwarten marmersteen al dat hier ghescreven staet.

Van sinte maertinsdaghe toot vastenavent, zo es toflaet ghedobbleert, van vastenavonde toot paesschen alle daghe drievoudt. Salich zyn zy die dit groot oflaet verdienen moghen ende die grote quarynen dier daer te halene zyn zonder ghetal.

(De aflaten in de mindere kerken).

Dit naervolghende zyn pardoenen die te halene zyn in diversche kerken ende cappellen binnen Rome.

In sinte pieters kerke ad vincula daer ziin de ketenen daer hy mede ghebonden was, daer gaf de paeus pelagius upten eersten dach van ougstmaend oflaet van allen zonden.

Item in onze vrauwe kerke la rotunda upten derden dach van meye ende inde (f. $69 \mathrm{v}$ ) feeste van allen helighen es daer oflaet van allen zonden. Ende alle zondaghe en alle woensdaghe zyn daer iij ${ }^{\mathrm{c}}$ jaer oflaets.

Item in onser vrauwen kerke in ara celi daer es dat weerde beilde van onser vrauwe dat sinte lucas maecte, met grooter weerdichede als de groote pestilencie in Rome regneerde, de inghel van den marbersteene neech haer, ende de inghelen zonghen daert menich mensche hoorde onser vrauwen lof Regina celi letare alleluia etc.

In onser vrauwe kerke de populo zyn alle daghe $\mathrm{ij}^{\mathrm{c}}$ lxxiiij jaer oflaets ende $\mathrm{ij}^{\mathrm{c}}$ ende xiiij quaryn.

In onser vrauwe kerke de portica es een weerdich beilde van onser vrauwe dat noyt van gheene creature ghemaect en was maer ghebracht biden inghelen.

Item noch in onser vrauwe kerke transtibrim diemen heet fontayne daer de olie spranc ten tijde doe god ghebooren was. Inde octave van onser vrauwe (f. 70) daghe talfougste daer es oflaet van allen zonden.

In onser vrauwe kerke molendinis daer es dat weerdighe beilde van onser vrauwen dat van gheenen mensche ghemaect es maer byden inghelen daer ghebracht daer es alle jare $x^{c}$ daghen oflaets.

Item in sinte barthelmeeus kerke daer zyn lichame licht daer zyn .m. jaer oflaets ende up zynen dach es daer oflaet van allen zonden.

Item tsinte saba daer ligghen de keysers lichamen Titus ende Vaspasianus die Jherusalem wonnen ende destrueerden ende die de veronike brochten die machmen daer zien.

In de kerke marie nove daer es een ander beilde van onser 
vrauwe dat sinte luuc pingierde, daer zyn alle daghen iij $^{\bullet}$ jaer of laets.

In onse vrauwe kerke transpondiaca zyn twee calommen daer sinte pieter ende sinte (f. $70 \mathrm{v}$ ) pauwels an ghegheeselt waren.

In sinte maertins kerke in monialibus zyn $\mathrm{ijj}^{\mathrm{c}}$ jaer oflaets.

Inde kerke quatuor coronatorum es xltich jaer oflaets.

In sinte marcellius ende sinte pieters kerke es .m. jaer oflaets.

In sinte eustaes kerke, daer zyn lichame, zyn wyf ende twee van zynen kindren ligghen daer es iij $^{c}$ jaer oflaets.

In de kerke sinte angeli es iijc jaer oflaets.

In sinte benedictus kerke es $\mathrm{iij}^{\mathrm{c}}$ jaer oflaets.

Inde kerke ten .iij. fonteinen daer sinte pauwels onthooft was es .m. jaer oflaets ende alzo veel quarynen.

In sinte anastacius kerke es viijc jaer oflaets ende alzo veel quarynen ende tderdendeel verlatenesse van allen zonden.

In de kerke van onse vrauwe diemen heet scala celi daer zyn de lichamen vanden $\mathrm{x}^{\mathrm{m}}$ (f. 71) martelaren ende priesters die daer devotelic messe celebreren tsy voor levenden ofte voor doden zynde in state van gracie, zyn gheabsolveert a pena ende a culpa, gheconfirmeirt van $\mathrm{lxvj}$ paeuzen die alle martelaere storven daer of datter vele lichamen ligghen in sinte sebastiaens kerke.

In sinte silvesters kerke daer es thooft van sinte jan baptiste, daer zyn te halen $\mathrm{x}^{\mathrm{e}}$ jaer oflaets ende alzo vele quarynen.

In sinter Niclaeus kerke in lateribus zyn .c. jaer oflaets ende zo vele quarynen.

In shelichs gheests kerke es vij ${ }^{c}$ jaer oflaets ende tvierdendeel van alle zonden quite.

In sinte cecilie kerke daer es de vyngher van sinte marie magdaleene ende de vyngher van sinter Niclaeus daer es .c. jaer oflaets.

In sinte jans kerke ad portam latinam daer hy ghezoden was in dolye up dien dach (f. 71v) haeltmen daer een ziele huuten vagheviere.

Inde kerke vanden xij apostelen inden hooghen outaer daer ligghen de lichamen vanden apostelen van sinte philippus ende van sinte jacops ende vele andre reliquien.

Inde cappelle domine quo vadis daer zyn de voorstappen ons heeren daer es .m. jaer oflaets.

In sinte potenciane kerke daer es de banc daer ons heere up zat met zynen jongheren, daer es .m. jaer oflaets.

In sinte Agniete kerke es .m. jaer oflaets.

In sinte praxeden kerke daer es tderdendeel vander calomme ons heeren, daer es tderdendeel verlatenesse van allen zonden. 
In sinte jooris kerke daer zyn hooft es, zyn glavie ende zyn baniere daer es .m. jaer oflaets.

In sinte katheline kerke daer es .m. jaer oflaets.

In sinte lysbette kerke es .c. jaer oflaets.

In sinte pieternelle kerke es .c. jaer oflaets.

In sinte crisogonus kerke zyn vele reliquien (f. 72) ende daer es .m. jaer oflaets.

In sinte bibiane kerke daer es teruudt dat noch wast dat zoe plante met haren propren handen en het gheift beete jeghens tgrote evele.

In sinte ignacius clooster es $\mathbf{j}$ weerdich beilde van onser vrauwe, daer es inde cappelle libera nos a pena et a culpa daer de drake onder ghebonden was daer es .m. jaer oflaets.

Item inde vastene $\mathrm{zyn}$ de oflaten alle ghedobbleirt.

Item waert alzo dat gheviele dat enich pelgrim storve up den wech waert int gaen of int keeren hy wort ghewaerlike gheabsolveirt van allen zonden etc.

Scriptum per me Rumoldum de doppere presbiterum in artibus magistrum anno $1490^{\circ}$

DOPPERE

Handschrift (autograaf) van De Doppere. Bewaard op het archief van de Commissie van Openbare Onderstand te Brugge. 